\title{
ARTICLE \\ Chip-scale gas chromatography: From injection through detection
}

\author{
Muhammad Akbar ${ }^{1}$, Michael Restaino ${ }^{1,2}$ and Masoud Agah ${ }^{1}$
}

Miniaturized gas chromatography $(\mu \mathrm{GC})$ systems hold potential for the rapid analysis of volatile organic compounds (VOCs) in an extremely compact and low-power enabled platform. Here, we utilize microfabrication technology to demonstrate the single chip integration of the key components of a $\mu \mathrm{GC}$ system in a two-step planar fabrication process. The $1.5 \times 3 \mathrm{~cm}$ microfluidic platform includes a sample injection unit, a micromachined semi-packed separation column ( $\mu \mathrm{SC}$ ) and a micro-helium discharge photoionization detector ( $\mu$ DPID). The sample injection unit consists of a T-shaped channel operated with an equally simple setup involving a single three-way fluidic valve, a micropump for sample loading and a carrier gas supply for subsequent analysis of the VOCs. The innovative sample injection technique described herein requires a loading time of only a few seconds and produces sharp and repeatable sample pulses (full width at half maximum of approximately $200 \mathrm{~ms}$ ) at a carrier gas flow rate that is compatible with efficient chromatographic separation. Furthermore, our comprehensive characterization of the chip reveals that a wide variety of VOCs with boiling points in the range of $110-216^{\circ} \mathrm{C}$ can be analyzed in less than 1 min by optimizing the flow and temperature programming conditions. Moreover, the analysis of four VOCs at the concentration level of one part per million in an aqueous sample (which corresponds to a headspace concentration in the lower parts-per-billion regime) was performed with a sampling time of only $6 \mathrm{~s}$. The $\mu$ DPID has demonstrated a linear dynamic range over three orders of magnitude. The system presented here could potentially be used to monitor hazardous VOCs in real time in industrial workplaces and residential settings.

Keywords: gas chromatography; lab-on-a-chip; MEMS; microsystem

Microsystems \& Nanoengineering (2015) 1, 15039; doi:10.1038/micronano.2015.39; Published online: 21 December 2015

\section{INTRODUCTION}

Over the past several decades, the progress in microfabrication technology has revolutionized the fields of computing and signal processing as well as the automobile industry. The miniaturization of well-established analytical instruments is another paradigm in which the use of this technology has produced significant advancements. One such example is the gas chromatography (GC) system, which is used in various scientific, medical, and industrial settings to separate and analyze volatile organic compounds (VOCs). The monitoring of VOCs is of interest in various applications, including homeland security, space and fossil fuel exploration, worker exposure assessment, and biomedical diagnostics $^{1-8}$. Miniaturized GCs ( $\mu \mathrm{GCs}$ ) are being intensely developed to enable the rapid diagnosis of VOCs in remote locations with low cost and low consumption. A typical $\mu \mathrm{GC}$ consists of three important components: an injector/pre-concentrator for sample introduction $^{9,10}$, a micromachined column for VOC separation ${ }^{11,12}$ and a single detector or array of detectors ${ }^{13,14}$ located at the column exit to identify the separated compounds.

The majority of standalone $\mu \mathrm{GC}$ systems reported to date address the manual assembly of separately fabricated $\mu \mathrm{GC}$ components using commercially available off-chip fluidic interconnects $^{15-19}$. This approach is commonly known as the hybrid integration method. The hybrid integration method has certain benefits, such as the optimization of components and the absence of thermal crosstalk between individual $\mu \mathrm{GC}$ components. Nevertheless, the implementation of $\mu \mathrm{GC}$ systems in a hybrid format is time consuming, cumbersome, expensive, and prone to error. In addition, the hybrid format degrades the overall performance of $\mu \mathrm{GCs}$ due to the presence of cold spots between transfer lines. The condensation of compounds in these cold spots can result in extensive peak broadening. In particular, high boilers experience peak broadening in a more profound manner, which can negatively impact their analysis. In contrast, a chipscale GC system, in which all three components are located on a single chip, may suffer from thermal crosstalk between the individual $\mu G C$ components. Thermal crosstalk can occur during two chromatographic events: (1) the desorption process of the pre-concentrator and (2) the temperature programming of the column. Thermal crosstalk could potentially change the retention time of a compound and also produce undesirable drift or noise in the detector signal. Fortunately, these issues can be avoided in the chip-scale GC platform by developing an optimal back-end detector technology.

Recently, there have been significant advancements in detector technology, and a wide variety of chemical detectors have been developed ${ }^{13,14,20-27}$. The micro-helium discharge photoionization detector ( $\mu \mathrm{DPID})$ presented by our group has demonstrated a minimum detection limit of approximately $10 \mathrm{pg}$, which is the same as that of a flame ionization detector (FID), which is mainly used in bench-top GC systems ${ }^{28}$. This high sensitivity of $\mu$ DPIDs reduces the system's reliance on the front-end pre-concentration step, which is typically performed to improve the detection limit of the detector. In addition, we have previously demonstrated that the $\mu D P I D$ can be easily integrated with the separation column and demonstrated its operation under the temperature

${ }^{1}$ VT MEMS Laboratory, Bradley Department of Electrical and Computer Engineering, Virginia Tech, Blacksburg, VA 24061, USA and ${ }^{2}$ Department of Biomedical Engineering and Mechanics, Virginia Tech, Blacksburg, VA 24061, USA

Correspondence: Masoud Agah (agah@vt.edu)

Received: 16 July 2015; revised: 1 November 2015; accepted: 11 November 2015 
and flow rate programming conditions ${ }^{28}$. These two features of $\mu D P I D s$ make them a promising candidate for developing chipscale GC systems, thereby addressing the above-mentioned issues and improving the overall cost and performance of this technology.

The first $\mu \mathrm{GC}$, which was developed in 1979 by Terry and coworkers ${ }^{29}$, included a monolithic integrated sample injection loop, a $1.5 \mathrm{~m}$ long separation column, and a separately fabricated thermal conductivity detector (TCD). Their hybrid $\mu \mathrm{GC}$ system required the TCD to be integrated after fabrication. In addition, TCDs generally have poor sensitivity (e.g., detection limit of 10 parts per million in Terry's work) and also produce an unstable baseline when operated under flow and temperature programming conditions (the TCD temperature must be controlled to $\pm 0.1{ }^{\circ} \mathrm{C}$ or better for baseline stability $)^{30}$. Sandia National Laboratories launched $\mu \mathrm{Chem} \mathrm{Cb}^{\mathrm{TM}}$ for homeland security applications in $1998^{31}$. Their research is unique in that it was focused on the development of a truly monolithic integrated $\mu \mathrm{GC}$ system. Their system included a preconcentrator, a separation column $(86 \mathrm{~cm}$ long, $100 \mu \mathrm{m}$ wide, and $400 \mu \mathrm{m}$ deep) and a magnetically actuated pivot plate resonator (PPR) fabricated on a silicon-oninsulator wafer. Although the fabrication and subsequent coating mechanism for the integrated chip were demonstrated, no chromatogram was published using an on-chip PPR detector ${ }^{32}$.

This paper is intended to demonstrate a truly compact chipscale GC platform that has dimensions of $1.5 \mathrm{~cm} \times 3 \mathrm{~cm}$. This labon-a-chip GC has three essential elements-a sample injector, separation column, and detector-all on the same platform. Our results indicate that a loading time of a few seconds is required to introduce a VOC mixture into the chip, with the subsequent analysis performed in less than a minute for compounds with a wide range of boiling points $\left(110-216^{\circ} \mathrm{C}\right)$. This development will be particularly suitable for producing low-cost and efficient $\mu G C$ systems for the rapid analysis of compounds in real-time situations.

\section{System description}

Figure 1a illustrates the configuration of fluidic connections between the chip, valve, miniaturized pump, and helium carrier gas supply. The valve position and pump are controlled by an b

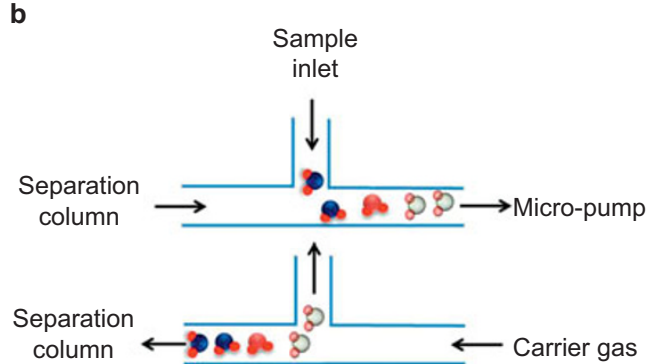

c

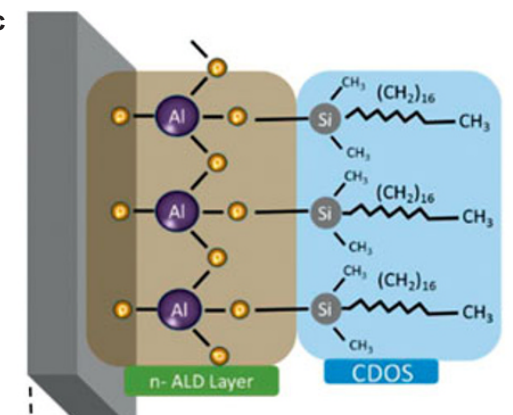

d

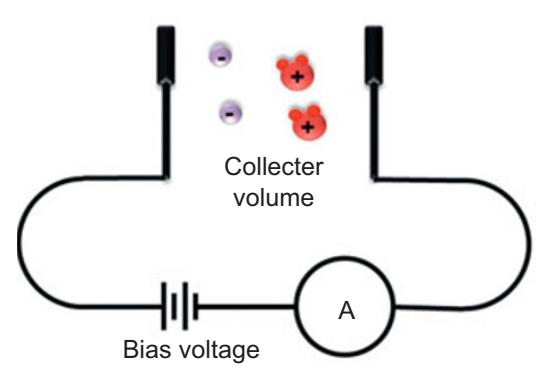

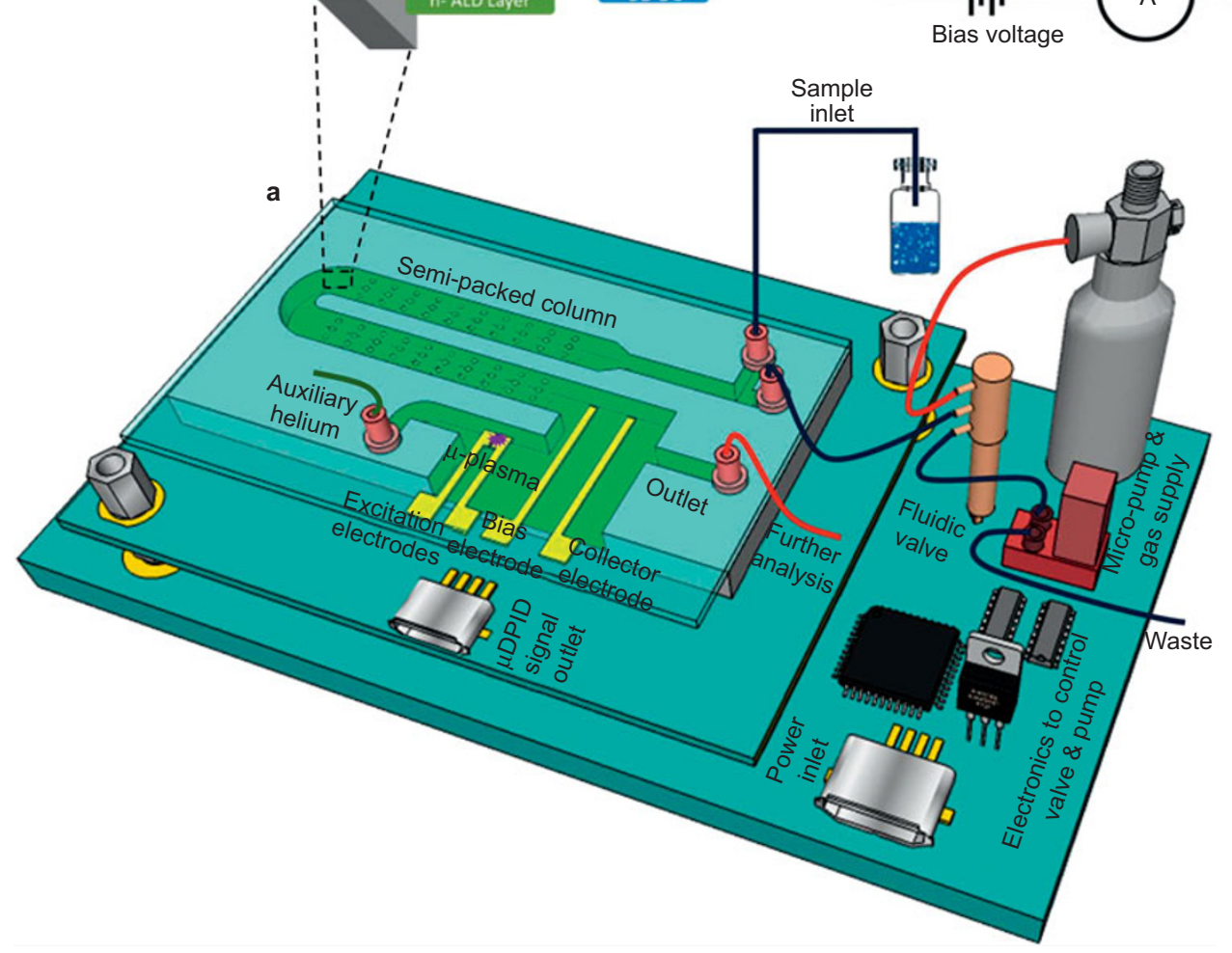

Figure 1 Conceptual image describing the major components of the chip-scale GC platform: (a) setup showing the configuration of fluidic interconnections between the chip, valve, micropump, and carrier gas; (b) description of the injection mechanism: the top image shows the loading phase, whereas the bottom one shows the injection phase; (c) coating mechanism for the $\mu \mathrm{SC}$; (d) electrical circuit for measuring the current signal produced by the ionization of VOCs. This figure is not drawn to scale. The size of the helium cylinder can be customized according to the requirements of the application. 
eight-bit microcontroller interfaced with a keypad to initiate the command. The operation of the chip-scale GC platform is quite straightforward. In normal operation, the valve is connected to the carrier gas supply. The sample inlet port is manually inserted into a sealed vial containing the unknown mixture of VOCs. To avoid liquid phase injection, the sample inlet port is kept in the headspace volume above the sample. To perform an injection, a single command from the keyboard initiates a sequence of events, which is completed within a few seconds. First, the valve is switched to the pump position, and the pump is turned on. The pump applies a negative pressure (flow rate of $1 \mathrm{~mL} \mathrm{~min} \mathrm{~m}^{-1}$ ) to load the sample into the fluidic channel (internal volume of approximately $1.2 \mu \mathrm{L}$ ) connecting the valve and chip. Then, the valve position is turned again to the carrier gas position, which injects the sample into the $\mu \mathrm{SC}$ (Figure $1 \mathrm{~b}$ ). The sample moves through the $\mu \mathrm{SC}$ with helium carrier gas and is separated into individual compounds. The separation process is based on the relative solubility of the compounds in the silane-treated alumina stationary phase (Figure 1c) and their relative vapor pressures. As the compounds separated in space and time elute from the $\mu \mathrm{SC}$, they are ionized with high-energy $(>10 \mathrm{eV})$ photons. These photons are generated through a microplasma produced in helium by applying a direct current (DC) voltage of $550 \mathrm{~V}$ across a pair of excitation electrodes. The gap between the excitation electrodes is approximately $20 \mu \mathrm{m}$. The microplasma is sustained by a constant supply of helium from the auxiliary channel. A $50 \mathrm{M}$ $\Omega$ ballast resistor is connected in series with the excitation electrode to limit the current flow, which could potentially damage the electrodes. In addition to the pair of excitation electrodes, the detector has a bias and collector electrode. The bias and collector electrodes are $1.5 \mathrm{~mm}$ apart, and the space between them is called the collector volume. The circuit shown in Figure $1 \mathrm{~d}$ measures the signal in the form of an electrical current, which is produced through the ionization of VOCs. Here, a picoammeter and the bias voltage are connected in series to the collector and bias electrode, respectively. The positive voltage applied to the bias electrode assists in capturing the electron inside the collector volume. The recombination of electrons with the ionized species can reduce the measured current. The current measured by the pico-ammeter is fed to the Keithley 2700 multimeter (Tektronix, Beaverton, OR, USA), which communicates with the LABVIEW program to plot the output signal.

\section{MATERIALS AND METHODS}

\section{Materials}

All VOCs listed in Table 1 were purchased from Sigma-Aldrich (St. Louis, MO, USA) with $>99 \%$ purity. Silicon wafers (n-type, 4 in diameter, $500 \mu \mathrm{m}$ thickness, single side polished) and Borofloat wafers (4 in diameter, $700 \mu \mathrm{m}$ thickness, double side polished) were purchased from University Wafers (Boston, MA, USA) and Coresix Precision Glass (Williamsburg, VA, USA), respectively. Ultra-high-purity helium was purchased from Airgas (Christiansburg, VA, USA). Fused silica capillary tubes (100 $\mu \mathrm{m}$ Inner Diameter and $200 \mu \mathrm{m}$ Outer Diameter) were purchased from Polymicro Technologies (Phoenix, AZ, USA). The miniaturized pump ( $\mathrm{P} / \mathrm{N}$ SP 270 EC-LC-L) and three-way latching solenoid valve (LHLA0521111H) were purchased from Schwarzer Precision (Essen, Germany) and Lee Company (Westbrook, CT, USA), respectively.

\section{Chip fabrication}

The chip fabrication follows similar processing steps as reported in our previous publication ${ }^{28}$. Each branch of the T-shaped sample injection unit is $2 \mathrm{~mm}$ long and $250 \mu \mathrm{m}$ wide. The T-shaped injection unit, separation stage ( $1 \mathrm{~m}$ long, $190 \mu \mathrm{m}$ wide, and $240 \mu \mathrm{m}$ deep with $20 \mu \mathrm{m}$ embedded circular pillars), fluidic
Table 1. Physical properties of the VOCs used in this study

\begin{tabular}{lccc}
\hline VOC & $p_{v}$ & BP & lonization potential \\
\hline Toluene & 22.0 & 110 & 8.82 \\
Tetrachloroethylene & 14.2 & 121 & 9.32 \\
Chlorobenzene & 11.7 & 131 & 9.07 \\
Ethylbenzene & 9.9 & 136 & 8.76 \\
$p$-xylene & 9.0 & 138 & 8.45 \\
$n$-nonane & 4.6 & 151 & 9.7 \\
Bromobenzene & 4.2 & 156 & 8.98 \\
$n$-decane & 1.4 & 174 & 9.6 \\
1,2-dichlorobenzene & 1.0 & 180 & 9.07 \\
$n$-undecane & 0.4 & 196 & 9.6 \\
1,2,4-trichlorobenzene & 0.3 & 214 & 9.04 \\
$n$-dodecane & 0.3 & 216 & - \\
\hline
\end{tabular}

$p_{\mathrm{v}}$ : vapor pressure $\left(\mathrm{mm}\right.$ of $\mathrm{Hg}$ ) at $20^{\circ} \mathrm{C}$. IP: ionization potential $(\mathrm{eV})$.

ports and cavity for the detector were fabricated in silicon using the bulk micromachining technique. Atomic layer deposition was used to coat a thin layer of alumina (approximately $10 \mathrm{~nm}$ ) at $250{ }^{\circ} \mathrm{C}$, which serves as a stationary phase. The detector electrodes were fabricated on the Borofloat wafer by evaporating $700 \mathrm{~nm} / 40 \mathrm{~nm}$ of $\mathrm{Ti} / \mathrm{Au}$. The silicon and Borofloat wafers were diced, and the individual devices were bonded together. Next, the detector cavity was sealed with epoxy, electrical wires were soldered to the bond pads and capillary tubes were inserted into the four ports of the chip. A solution containing $10 \mathrm{mM}$ chlorodimethyloctadecylsilane in toluene was filled in the $\mu \mathrm{SC}$ and left at room temperature for $24 \mathrm{~h}$. Finally, the solution was purged with nitrogen for $30 \mathrm{~min}$. The $\mu \mathrm{SC}$ was conditioned inside the conventional GC system for approximately $1 \mathrm{~h}\left(35^{\circ} \mathrm{C}\right.$, ramped at $2{ }^{\circ} \mathrm{C} \min ^{-1}$ to $140{ }^{\circ} \mathrm{C}$ ) at a constant helium pressure of $10 \mathrm{psi}$.

\section{RESULTS AND DISCUSSION}

The top and cross-sectional images of the $\mu S C$ using scanning electron microscopy (SEM) are shown in Figure $2 a$ and $b$, respectively. The optical image of the packaged device is shown in Figure 2c with the capillaries attached to all four ports of the chip and the electrical connections in place. We first explain the performance evaluation of the sample injection unit and $\mu$ DPID. Both components were diced from the integrated chip for that purpose. Then, the chromatographic analysis performed using the integrated chip will be demonstrated.

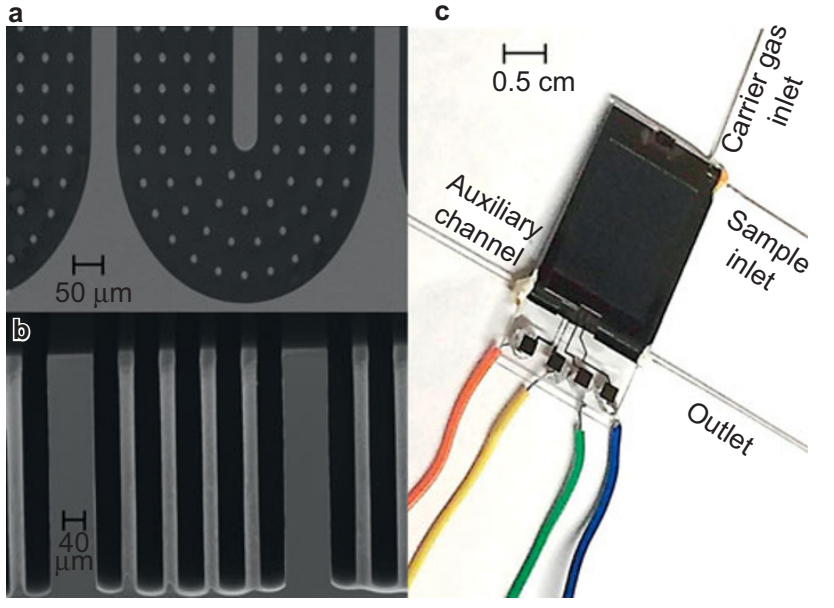

Figure 2 SEM images of the semi-packed $\mu S C$ column showing (a) a top view of the channel with embedded $20 \mu \mathrm{m}$ circular micropillars; (b) a cross-sectional view showing high-aspect-ratio pillars; (c) an optical image of the packaged chip. 


\section{Evaluating sample injection unit}

The performance of the sample injection unit was characterized in terms of the peak parameters (full width at half maximum (FWHM), peak height, and area). Five compounds-heptane, toluene, chlorobenzene, ethylbenzene, and $p$-xylene-were used in these tests. Each compound was separately injected at flow rates set to five discrete values of $0.3,0.45,0.72,1$, and $1.4 \mathrm{~mL} \mathrm{~min}$. These flow rates correspond to inlet pressures of $10,15,20,25$, and $30 \mathrm{psi}$. The loading time of $500 \mathrm{~ms}$ was used for all VOCs. The outlet of the injector was connected to the FID installed in the conventional GC system (HP 7890). Triplicate runs were performed for each value, and the average values of the FWHM and peak height were plotted, as shown in Figure 3.

The results illustrate that for all VOCs, the FWHM depends on the injector flow rate condition. All compounds experienced a sharp decrease in FWHM between 0.3 and $0.72 \mathrm{~mL} \min ^{-1}$ followed by a more gradual decrease. A similar trend has been observed previously ${ }^{14}$ and in our experiments when a $20 \mathrm{~cm}$ long uncoated capillary tube was connected between a conventional GC injector and the FID. The inverse proportionality of the FWHM with the flow rate can be attributed to different factors. First, increasing the carrier gas flow rate will increase the sample injection rate from the sample loop to the detector, which reduces the extra-column band broadening. Second, the solutes are swept faster, and the longitudinal diffusion in the mobile phase is decreased as a result. Molecules diffuse in the carrier gas from the region of high concentration to that of lower concentration over time ${ }^{33}$. Increasing the flow rate decreases the time that molecules spend in the injector and connecting tubes, and therefore, the diffusion of molecules in the carrier gas decreases, which results in lower FWHM values. Furthermore, the on-chip injector tested herein operates at room temperature, which can contribute to the differences in the FWHM of high- and lowvolatility compounds. In summary, the overall decreases in the FWHM for heptane, toluene, chlorobenzene, ethylbenzene, and $p$-xylene over the entire flow rate range were $40 \%, 59 \%, 59 \%$, $50 \%$, and $64 \%$, respectively.

Because the FID is sensitive to the mass flow rate, the decrease in the FWHM was compensated for by a corresponding increase in the peak height to maintain uniform peak area. Figure $3 \mathrm{~b}$ shows that the peak height increases linearly over the entire flow rate range $\left(0.3-1.4 \mathrm{~mL} \mathrm{~min}^{-1}\right)$ for all VOCs. This increase in the peak height is attributed to the increase in mass over time, as measured by the FID. The peak area for all compounds remained approximately constant for all flow rate conditions. Peak areas were calculated to be approximately $20 \mathrm{pA} \times \mathrm{s}$ for these compounds except for ethylbenzene, which had a peak area of $35 \mathrm{pA} \times \mathrm{s}$.

Furthermore, the repeatability of the sample injection unit was investigated by monitoring the change in the peak parameters (FWHM, peak height, and area) over multiple headspace injections. For this purpose, toluene was chosen as a test compound, and multiple injections were performed in succession approximately every $30 \mathrm{~s}$. The flow rate in this experiment was set to $1.4 \mathrm{~mL} \mathrm{~min}^{-1}$. The sample injection unit produced highly repeatable results, with less than $5 \%$ variation in the standard error values for peak parameters over six injections. The FWHMs for these injections were approximately $200 \mathrm{~ms}$.

\section{Linearity of the $\mu$ DPID}

The previous characterization of the $\mu$ DPID has provided encouraging results, indicating a minimum detection limit of approximately $10 \mathrm{pg}$, a response time of approximately $200 \mathrm{~ms}$ and highly stable excitation electrodes over a long period of time ${ }^{28}$. Next, we experimentally analyzed the linear detection range of the detector.

To evaluate the linear range of the $\mu D P I D$, the inlets of the detector were connected to injectors $A$ and $B$ of the conventional GC system. The pressures of injectors $A$ and $B$ were set to 15 and $10 \mathrm{psi}$, respectively. A direct current (DC) voltage of $550 \mathrm{~V}$ was applied (using PS-310, Stanford Research Systems, Sunnyvale, CA, USA) to create the discharge, and the bias voltage was set to 30 $\mathrm{V}$. This value of the bias voltage was selected based on our previous work, which showed the enhanced sensitivity of the detector at $30 \mathrm{~V}^{28}$. Four test compounds-toluene, tetrachloroethylene, chlorobenzene, and ethylbenzene-were used. The different headspace volumes of the test compounds sealed in a vial were sampled using an autosampler (7359A) module to ensure repeatable injections. Assuming ideal gas law behavior, the mass of the compound injected from a saturated vapor above the pure liquid could be calculated from the injection volume and split ratio used for the injection. The injected mass was in the range of $10 \mathrm{pg}$ to $10 \mathrm{ng}$. The response of the detector was measured in terms of the peak area for each injection. The peak area was selected as an indicator for the quantitative data
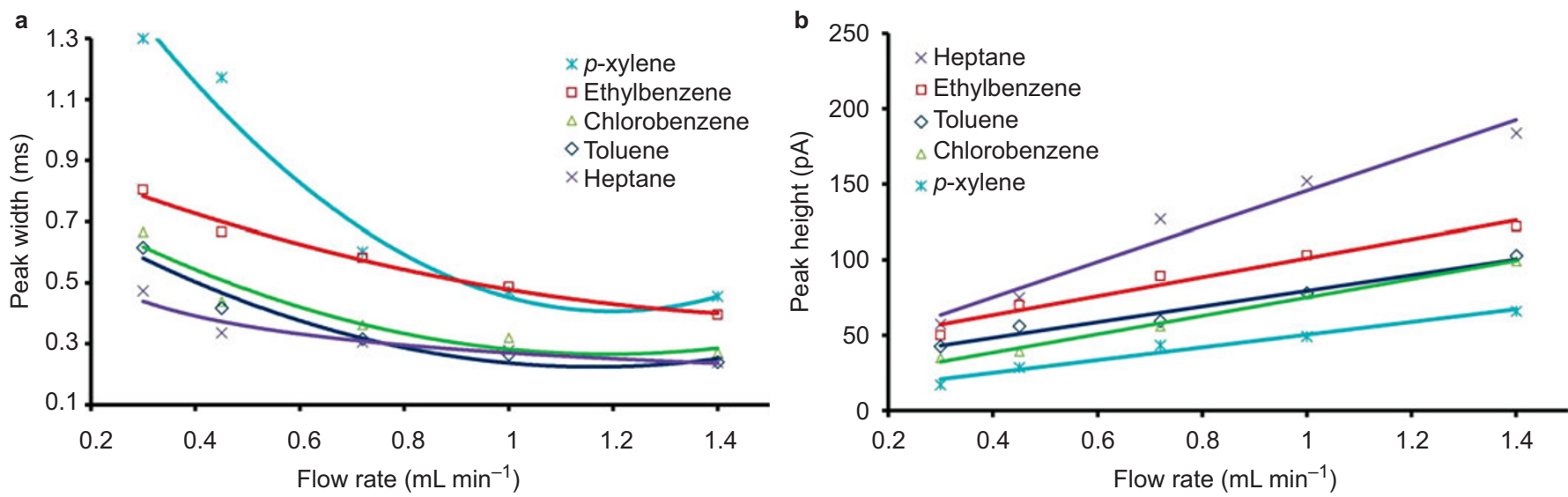

Figure 3 (a) Effect of the carrier gas flow rate on the FWHM value of the injection plug. The curves were approximated with a polynomial trend line of order two. The R-squared values were $0.88,0.96,0.91,0.98$, and 0.97 for heptane, toluene, chlorobenzene, ethylbenzene, and p-xylene, respectively. The standard error calculated for each point over triplicate runs were $<10 \%$, showing that the sample injection unit produces repeatable injections. (b) Effect of the carrier gas flow rate on the peak height of the injection plug. The curves were approximated with a linear trend line. The R-squared values were $0.96,0.96,0.99,0.96$, and 0.97 for heptane, toluene, chlorobenzene, ethylbenzene, and $\mathrm{p}$-xylene, respectively. The standard errors calculated for each point over triplicate runs were $<10 \%$. 
analysis (instead of peak height) based on our previous results, which indicated that the $\mu D P I D$ is a mass flow rate-sensitive detector (MSD) ${ }^{28}$. For any MSD, variations in the flow rate could give rise to changes in the peak height or width; however, negligible changes are observed in the peak area. Therefore, the quantification of a compound in terms of peak area is more accurate. Each data point was repeated three times, and the average peak area was plotted against the injected mass of each test compound (Figure 4a). Because the injected mass extends over several orders of magnitude, these curves have been plotted on a log-log scale for clarity (Figure $4 b$ ).

These results illustrate that the response of the detector remains linear to the injected mass of the test compounds over three orders of magnitude. The R-squared values and their respective slopes obtained by linear regression analysis (forced zero Y-intercept) have been indicated for each curve. Moreover, as evident from Figure $4 \mathrm{~b}$, as the injected mass increased by three orders of magnitude, the sensing signal also increased by 1,000 fold, showing that the linear response of the $\mu$ DPID spans over three orders of magnitude. The response of $\mu$ DPID is lower for tetrachloroethylene due to its high ionization potential, which makes it difficult to ionize. The ionization potentials of the remaining VOCs are reasonably close. The ionization potentials for all VOCs used in this report are provided in Table 1.

The sensitivity of the detector is defined as the signal output per unit mass of the compound in the carrier gas. For MSDs, the sensitivity $S$, is defined as:

$$
S=\frac{A}{W}
$$

where $A$ is the integrated peak area, and $W$ is the mass of the compound. Therefore, the slopes of the curves in Figure $4 a$ indicate the sensitivity of the $\mu$ DPID for the particular compounds under investigation. The slopes for tetrachloroethylene, toluene, chlorobenzene, and ethylbenzene were $0.036,0.0488,0.0841$, and 0.2171 (A.s $\mathrm{g}^{-1}$ ), respectively, showing the higher sensitivity of the $\mu$ DPID toward ethylbenzene compared to the other test compounds.

\section{Chip-scale GC: Chromatographic analysis}

The chip-scale GC platform was tested following the characterization of the sample injection unit and $\mu D P I D$. Twelve VOCs - toluene, tetrachloroethylene, chlorobenzene, ethylbenzene, $p$-xylene, n-nonane, bromobenzene, $n$-decane, 1,2-dichlorobenzene, $n$-undecane, 1,2,4trichlorobenzene, and $n$-dodecane-were selected to evaluate the performance of the chip. The following experiments were performed to demonstrate the sampling, separation and detection of compounds with boiling points in the range of $110-216{ }^{\circ} \mathrm{C}$ as quickly as possible through the optimization of the flow and temperature programming conditions.

The chip was configured as discussed in the system description section (Figure 1), with the carrier gas and auxiliary helium supplied by the conventional GC system. The pressures on these supplies were set to 22 and 10 psi, respectively, corresponding to

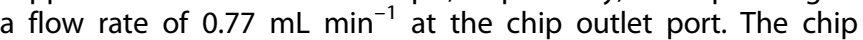
temperature was maintained at $40^{\circ} \mathrm{C}$. During sampling, the pump was turned on to load the sample into the fluidic connection between the chip and the valve. A sampling time of $3 \mathrm{~s}$ was considered sufficient for testing the compounds. The chromatogram in Figure 5 shows the successful identification of nine compounds in $2.5 \mathrm{~min}$, providing good resolution and retention of the compounds. The compounds were eluted in order of decreasing vapor pressure (the $p_{v}$ values are provided in Table 1). The compounds with high vapor pressure tend to remain in the vapor state and thus have more affinity for the mobile phase compared to the stationary phase, which results in their early elution from the $\mu \mathrm{SC}$. In Figure 5, n-nonane and bromobenzene were not resolved because their vapor pressures were relatively close. A similar observation was made for $n$-decane and 1,2dichlorobenzene.The air peak detected by the $\mu$ DPID was removed from the chromatogram for clarity. The peak width at the base $\left(w_{\mathrm{b}}=4 \sigma\right)$ and the retention time $\left(t_{\mathrm{r}}\right)$ were calculated for every compound from the chromatograms generated by the $\mu \mathrm{DPID}$. The $w_{\mathrm{b}}$ values for $p$-xylene, $C_{9} /$ bromobenzene, and $C_{10} /$ 1,2-dichlorobenzene,all of which have high boiling points, were $7.2,10$, and $27 \mathrm{~s}$, respectively. The resolution $\left(R_{\mathrm{s}}\right)$ is defined as

$$
R_{\mathrm{S}}=\frac{\left(t_{\mathrm{r}}\right)_{B}-\left(t_{\mathrm{r}}\right)_{A}}{\left((4 \sigma)_{A}+(4 \sigma)_{B}\right) / 2}=\frac{2 d}{(4 \sigma)_{A}+(4 \sigma)_{B}}
$$

where $d$ is the distance between the peak maxima for the two compounds, $A$ and $B$. The resolution between $p$-xylene and $C_{9} /$ bromobenzene was 2.16, and that between $C_{9} /$ bromobenzene and $\mathrm{C}_{10}$ was 4.60 .

To reduce the analysis time and increase the peak width of the high-boiling-point compounds, a series of experiments was
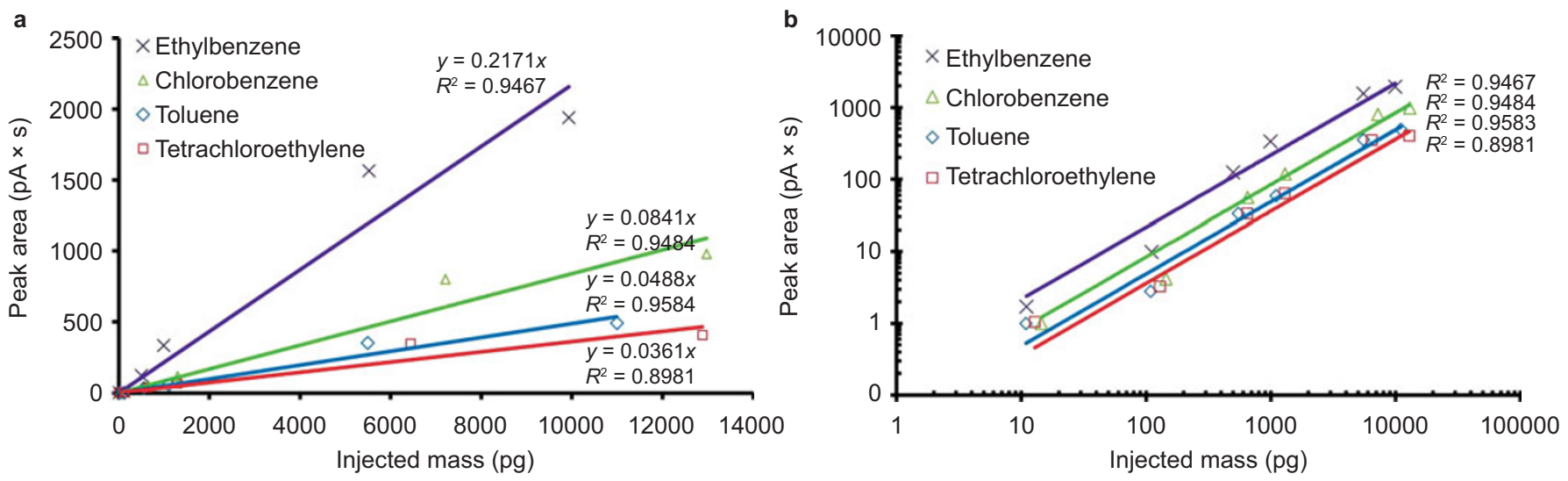

Figure 4 (a) Calibration curves for the $\mu$ DPID produced by injecting different masses (10 pg-13 ng) of four test compounds and calculating the response (peak area). Each point was repeated in triplicate, and the average value was plotted against the injected mass. Linear regression (forced zero $Y$-intercept) $R^{2}$ values are shown for each compound. The slopes (A.s $\mathrm{g}^{-1}$ ) were $0.0361,0.0488,0.0841$, and 0.2171 for tetrachloroethylene, toluene, chlorobenzene, and ethylbenzene, respectively. (b) Corresponding curves plotted on a log-scale for clarity. 

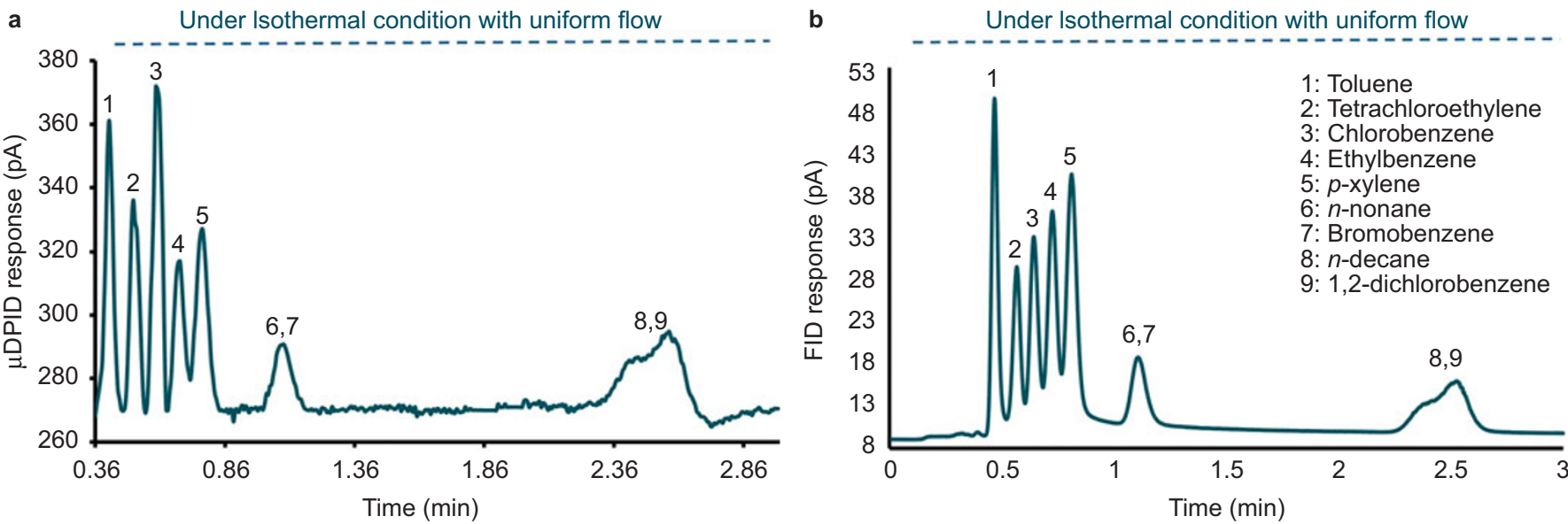

Figure 5 (a) Response of the $\mu \mathrm{DPID}$ to a $3 \mathrm{~s}$ headspace sampling of a nine-compound mixture under isothermal conditions at $40{ }^{\circ} \mathrm{C}$ and a

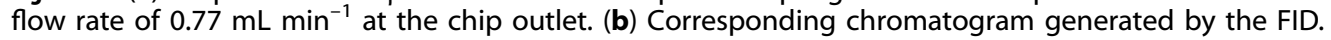

performed under flow programming conditions. One of the best chromatographic results is shown in Figure 6a. Here, the pressure was initially set to $22 \mathrm{psi}\left(0.77 \mathrm{~mL} \mathrm{~min}^{-1}\right)$ for $0.7 \mathrm{~min}$ and then ramped up to $35 \mathrm{psi}\left(1 \mathrm{~mL} \mathrm{~min}^{-1}\right)$ at a rate of $35 \mathrm{psi} \mathrm{min}^{-1}$. The holdup time was necessary to avoid poor resolution between the first five eluting compounds. In Figure $6 a$, the first nine compounds eluted in $1.6 \mathrm{~min}$, which shows a reduction in the analysis time of $36 \%$ compared to the previous run. In addition, the $C_{11}$ peak was observed at $2.8 \mathrm{~min}$. The increased pressure also had a profound impact on the $w_{\mathrm{b}}$ value for high-boiling-point compounds, including $p$-xylene, $C_{9} /$ bromobenzene, and $C_{10} / 1,2-$ dichlorobenzene. Reductions in $w_{\mathrm{b}}$ of $33 \%, 40 \%$, and $69 \%$ were observed for these compounds, respectively. These reductions occur because at increased pressure, less time is available for the longitudinal diffusion of molecules inside the $\mu \mathrm{SC}$, which results in a narrower peak width. The $R_{\mathrm{s}}$ values between $p$-xylene and $\mathrm{C}_{9} /$ bromobenzene, between $C_{9} /$ bromobenzene and $C_{10} / 1,2$-dichlorobenzene, and between $C_{10} / 1,2$-dichlorobenzene and $C_{11}$ were reduced to $2,4.08$, and 8.16 , respectively.

Temperature is one of the most important variables in GCs and an effective way of optimizing the analysis time. The superposition of temperature $\left(T_{\text {initial }}=40{ }^{\circ} \mathrm{C}\right.$, ramp $=30{ }^{\circ} \mathrm{C} \mathrm{min}-1, T_{\text {final }}=$ $\left.65^{\circ} \mathrm{C}\right)$ and flow programming $\left(P_{\text {initial }}=22 \mathrm{psi}\right.$, ramp $=35 \mathrm{psi} \mathrm{min}^{-1}$, $P_{\text {final }}=35$ psi) has been demonstrated in the chromatogram shown in Figure $6 \mathrm{~b}$. As a result, the analysis was completed in $1.8 \mathrm{~min}$ (56\% reduction in the analysis time). As expected, further decreases in $w_{\mathrm{b}}$ of $41 \%, 58 \%$, and $86 \%$ were observed for $p$-xylene, $\mathrm{C}_{9} /$ bromobenzene, and $\mathrm{C}_{10} / 1,2$-dichlorobenzene, respectively.

A separate sample containing high-boiling-point compounds, including $n$-nonane, bromobenzene, $n$-decane, 1,2-dichlorobenzene, $n$-undecane, 1,2,4-trichlorobenzene, and $n$-dodecane, was also analyzed. The carrier gas pressure was increased to $35 \mathrm{psi}$, whereas the auxiliary helium pressure was maintained at 10 psi respectively, which corresponds to a flow rate of $0.9 \mathrm{~mL} \mathrm{~min}^{-1}$ at the chip outlet port. The chip temperature was increased to $70{ }^{\circ} \mathrm{C}$. The loading time was increased to $6 \mathrm{~s}$ because of the low vapor pressure of these compounds. The resulting chromatogram is shown in Figure $6 \mathrm{c}$. The analysis was completed in $0.8 \mathrm{~min}$, with significantly lower values of $w_{\mathrm{b}} . w_{\mathrm{b}}$ values of $900 \mathrm{~ms}, 1.5 \mathrm{~s}, 2.4 \mathrm{~s}$, and $5.4 \mathrm{~s}$ were obtained for $C_{9} /$ bromobenzene, $C_{10} / 1$,2-dichlorobenzene, $C_{11}$ and 1,2,4-trichlorobenzene/ $C_{12}$, respectively. The data for retention time $\left(t_{\mathrm{r}}\right)$ and peak width $\left(w_{\mathrm{b}}\right)$ for these compounds in Figures $5 \mathrm{a}$ and $6 \mathrm{a}-\mathrm{c}$, respectively, have been compiled in Table 2. The resolutions $\left(R_{\mathrm{s}}\right)$ for the high-boiling-point compounds are listed in Table 3.

\section{Aqueous analysis}

The chip performance was also evaluated for the analysis of VOCs in aqueous media. Four VOCs - toluene, chlorobenzene, ethylbenzene, and $p$-xylene-were diluted to a concentration of 1 ppm $\left(1 \mathrm{mg} \mathrm{L}^{-1}\right)$ in deionized water. A small aliquot $(500 \mu \mathrm{L})$ of the prepared sample was transferred into a $1.8 \mathrm{~mL}$ vial. The vial was

Table 2. Summary of the retention time $\left(t_{r}\right)$ and peak width at the base $(4 \sigma)$ from the results presented in Figures $5 a$ and $6 a-c$ for the $\mu D P I D$

\begin{tabular}{|c|c|c|c|c|c|c|c|c|}
\hline & \multicolumn{2}{|c|}{ Isothermal, $40^{\circ} \mathrm{C}$} & \multicolumn{2}{|c|}{ Flow programmed run } & \multicolumn{2}{|c|}{$\begin{array}{c}\text { Flow and temperature } \\
\text { programmed run }\end{array}$} & \multicolumn{2}{|c|}{ Isothermal, $40^{\circ} \mathrm{C}$} \\
\hline & $t_{\mathrm{r}}(\mathrm{s})$ & $4 \sigma(\mathrm{s})$ & $t_{\mathrm{r}}(\mathrm{s})$ & $4 \sigma(s)$ & $t_{\mathrm{r}}(\mathrm{s})$ & $4 \sigma(s)$ & $t_{\mathrm{r}}(\mathrm{s})$ & $4 \sigma(\mathrm{s})$ \\
\hline Toluene & 24.6 & 4.2 & 24.0 & 6.0 & 24.6 & 4.8 & - & - \\
\hline Tetrachloroethylene & 30.6 & 4.8 & 29.4 & 4.8 & 30 & 4.8 & - & - \\
\hline Chlorobenzene & 36.0 & 4.8 & 34.2 & 4.8 & 34.8 & 4.2 & - & - \\
\hline Ethylbenzene & 40.8 & 5.4 & 40.8 & 4.8 & 39.0 & 4.2 & - & - \\
\hline p-xylene & 46.2 & 7.2 & 44.4 & 4.8 & 43.8 & 4.2 & - & - \\
\hline n-nonane \& bromobenzene & 64.8 & 10 & 55.2 & 6.0 & 52.8 & 4.2 & 3.60 & 0.9 \\
\hline n-decane \& 1,2-dichlorobenzene & 150 & 27 & 84.6 & 8.4 & 66 & 3.6 & 10.8 & 1.5 \\
\hline$n$-undecane & - & - & 168 & 12 & 108 & 9.0 & 28.2 & 2.4 \\
\hline 1,2,4-trichlorobenzene \& $n$-dodecane & - & - & - & - & - & - & 43.2 & 5.4 \\
\hline
\end{tabular}

The data presented were used to calculate $R_{\mathrm{s}}$. 
Table 3. Peak resolution $\left(R_{s}\right)$ calculated for high-boiling-point compounds, including $p$-xylene, $C_{9} /$ bromobenzene, $C_{10} / 1,2$-dichlorobenzene, $\mathrm{C}_{11}$, and 1,2,4-trichlorobenzene, presented in Figures $5 \mathrm{a}$ and $6 \mathrm{a}-\mathrm{c}$

\begin{tabular}{lcccc}
\hline Testing conditions & $p$-xylene- $\mathrm{C}_{9}$ & Bromobenzene- $\mathrm{C}_{10}$ & 1,2-dichlorobenzene- $\mathrm{C}_{11}$ & $\mathrm{C}_{11}-1,2,4$-trichlorobenzene \\
\hline Isothermal, $40^{\circ} \mathrm{C}$ & 2.16 & 4.60 & - & - \\
Flow programmer run & 2.0 & 4.08 & 8.16 & - \\
Flow and temperature programmed run & 2.14 & 3.38 & 6.66 & - \\
Isothermal, $70^{\circ} \mathrm{C}$ & - & 6.0 & 8.9 & 3.84 \\
\hline
\end{tabular}

subsequently sealed to avoid compromising the sample integrity. A sampling time of $6 \mathrm{~s}$ was considered sufficient for extracting VOCs from the headspace of the sample. The concentration in the headspace was calculated using Henry's Law. The headspace concentrations for toluene, chlorobenzene, ethylbenzene, and $p$ xylene were 270, 152, 323, and $314 \mathrm{ppb}$, respectively. The representative chromatogram is shown in Figure $6 d$, where the separation and detection were completed within $0.6 \mathrm{~min}$. The United States Environmental Protection Agency (EPA) has specified maximum contamination levels for toluene, chlorobenzene, ethylbenzene, and p-xylene of $1,0.1,0.7$ and $10 \mathrm{ppm}$, respectively. a
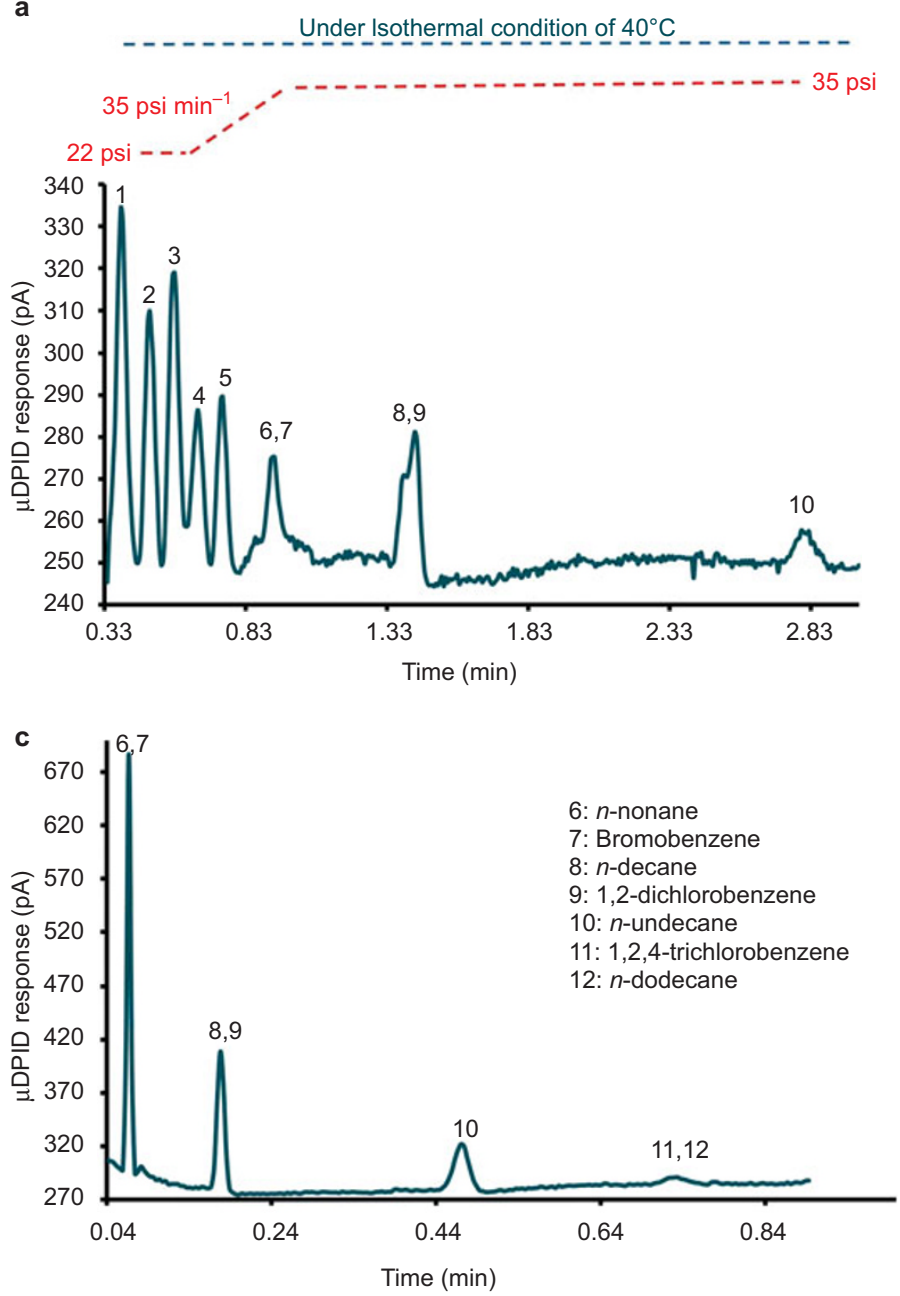

b

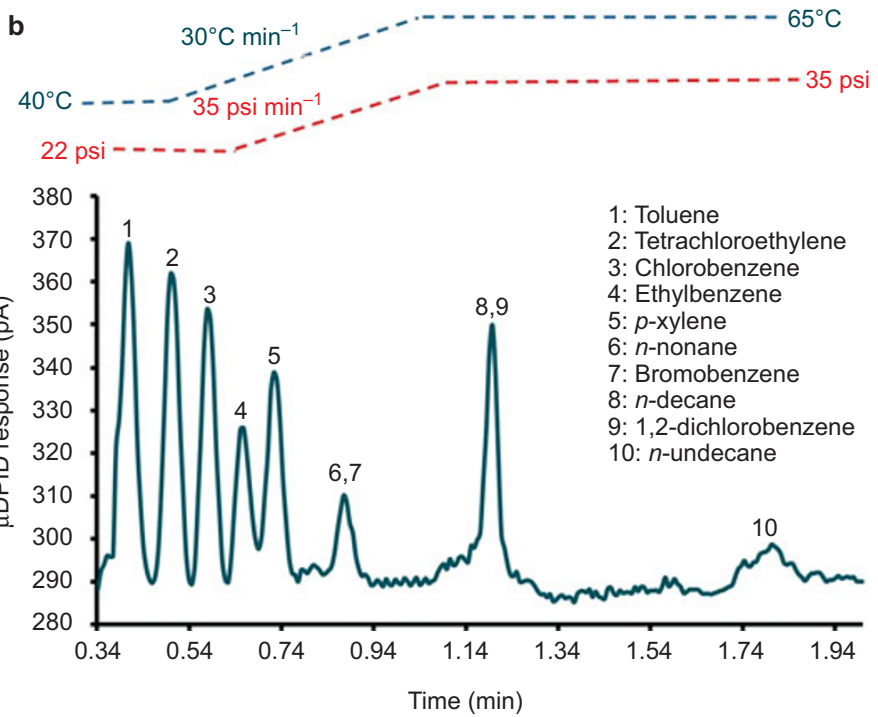

d

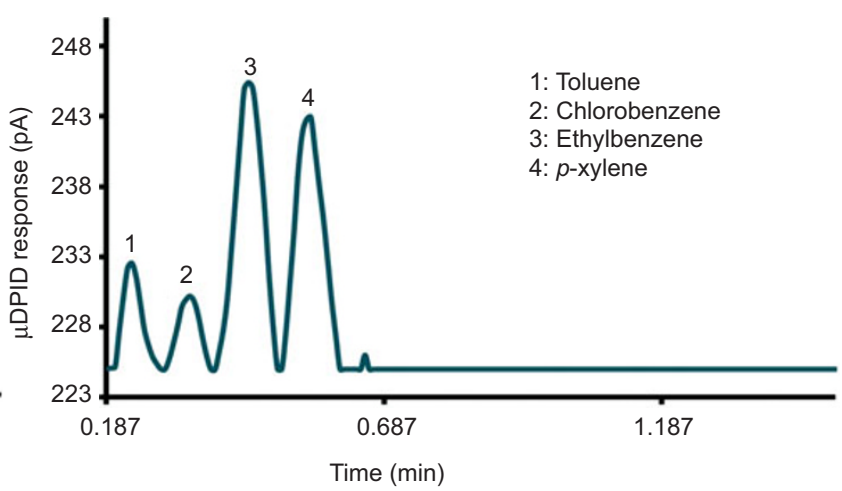

Figure 6 (a) Response of the $\mu$ DPID to a $3 \mathrm{~s}$ headspace sampling of a 10-compound mixture under the flow programming and isothermal conditions at $40^{\circ} \mathrm{C}$. The initial and final flow rates through the column outlet were $0.77 \mathrm{~mL} \mathrm{~min}^{-1}$ and $1 \mathrm{~mL} \mathrm{~min}-1$, respectively. (b) Response of the $\mu \mathrm{DPID}$ to a $3 \mathrm{~s}$ headspace sampling of a 10-compound mixture under the flow and temperature programming conditions. The initial and final flow rates through the column were 0.77 and $0.9 \mathrm{~mL} \mathrm{~min}^{-1}$, respectively. (c) Response of the $\mu$ DPID to a $6 \mathrm{~s}$ headspace sampling of a seven-compound mixture containing high-boiling-point compounds under isothermal conditions of $70^{\circ} \mathrm{C}$ and a flow rate of $0.9 \mathrm{~mL}$ min ${ }^{-1}$ at the chip outlet. (d) Response of the $\mu \mathrm{DPID}$ to a $6 \mathrm{~s}$ headspace sampling of a four-compound mixture diluted to a concentration of 1 ppm in the aqueous phase. The corresponding concentrations in the headspace calculated using Henry's Law are 270 (toluene), 152 (chlorobenzene), 323 (ethylbenzene), and $314 \mathrm{ppb}$ (p-xylene). The flow rate at the chip outlet was set to $0.77 \mathrm{~mL} \mathrm{~min}^{-1}$. 


\section{CONCLUSION}

This study presents an integrated $\mu G C$ analysis system that has all of the important features of a lab-on-a-chip platform. It has a sample injection unit, a microseparation column, and a detector, all of which are integrated on a $1.5 \mathrm{~cm} \times 3 \mathrm{~cm}$ platform. The integration of the $\mu G C$ components on a common substrate reduces the footprint of this technology, enhances the overall performance and allows for a lower fabrication cost. Furthermore, each component can perform its role effectively and rapidly; for example, the sample injection unit requires a loading time of a few seconds to produce sharp injections (FWHM of approximately $200 \mathrm{~ms}$ ). Similarly, the subsequent operation of the system under the temperature and flow programming conditions allows for a rapid analysis of complex VOC mixtures. In addition, the excellent detection limit (approximately $10 \mathrm{pg}$ ), response time (approximately $200 \mathrm{~ms}$ ), and linearity of the $\mu \mathrm{DPID}$ (three orders of magnitude) demonstrates its potential for use in $\mu \mathrm{GC}$ technology. Further improvements in these properties through modifications in the design of the $\mu$ DPID are also being considered. Although the miniaturization of the $\mu \mathrm{GC}$ system through the integration of microelectromechanical system components has been demonstrated in this work, we are also exploring its integration with electronic components to further miniaturize this technology.

\section{ACKNOWLEDGEMENTS}

The authors would like to thank Prof. Kang Xia (Department of Crop and Soil Environmental Sciences, Virginia Tech) and Professor Emeritus Dr. Harold McNair (Chemistry Department, Virginia Tech) for their technical discussions regarding the aqueous sample analysis. This work was partially supported by the National Institute for Occupational Safety and Health (NIOSH) under award No.

1R21OH010330 and Virginia Tech's Institute for Critical Technology and Applied Science (ICTAS).

\section{COMPETING INTERESTS}

The authors declare no competing interest.

\section{REFERENCES}

1 Wilson A. Electronic-nose applications in forensic science and for analysis of volatile biomarkers in the human breath. Journal of Forensic Science and Criminology 2014; 1: doi: 10.15744/2348-9804.1.S103.

2 Dorman FL, Whiting JJ, Cochran JW et al. Gas chromatography. Analytical Chemistry 2010; 82: 4775-4785.

3 Boots A, Smolinska A, van Berkel J et al. Identification of microorganisms based on headspace analysis of volatile organic compounds by gas chromatographymass spectrometry. Journal of Breath Research 2014; 8: doi:10.1088/1752-7155/8/ 2/027106.

4 Pietrogrande MC, Zampolli MG, Dondi F et al. In situ analysis of the Martian soil by gas chromatography: Decoding of complex chromatograms of organic molecules of exobiological interest. Journal of Chromatography A 2005; 1071: 255-261.

5 Oliveira CR, Ferreira AA, Oliveira CJ et al. Biomarkers in crude oil revealed by comprehensive two-dimensional gas chromatography time-of-flight mass spectrometry: Depositional paleoenvironment proxies. Organic Geochemistry 2012; 46: $154-164$.

6 Song G, Qin T, Liu H et al. Quantitative breath analysis of volatile organic compounds of lung cancer patients. Lung Cancer 2010; 67: 227-231.

7 Sottani C, Porro B, Comelli $\mathrm{M}$ et al. An analysis to study trends in occupational exposure to antineoplastic drugs among health care workers. Journal of Chromatography B 2010; 878: 2593-2605.

8 Giannoukos S, Brkić B, Taylor S et al. Membrane inlet mass spectrometry for homeland security and forensic applications. Journal of the American Society for Mass Spectrometry 2014: 8: 1-9.

9 James F, Breuil P, Pijolat C et al. Development of a MEMS preconcentrator for micro-gas chromatography analyses. Procedia Engineering 2014; 87: 500-503.
10 Camara M, Breuil P, Briand D et al. Preconcentration modeling for the optimization of a micro gas preconcentrator applied to environmental monitoring. Analytical Chemistry 2015; 87: 4455-4463.

11 Haudebourg R, Vial J, Thiebaut D et al. Temperature-programmed sputtered micromachined gas chromatography columns: An approach to fast separations in oilfield applications. Analytical Chemistry 2012; 85: 114-120.

12 Sun J, Cui D, Guan F et al. High resolution microfabricated gas chromatography column with porous silicon acting as support. Sensors and Actuators B: Chemical 2014; 201: 19-24.

13 Scholten K, Fan X, Zellers ET. A microfabricated optofluidic ring resonator for sensitive, high-speed detection of volatile organic compounds. Lab on a Chip 2014; 14: 3873-3880.

14 Zhong Q, Steinecker WH, Zellers ET. Characterization of a high-performance portable GC with a chemiresistor array detector. Analyst 2009; 134: 283-293.

15 Collin WR, Serrano G, Wright LK et al. Microfabricated gas chromatograph for rapid, trace-level determinations of gas-phase explosive marker compounds. Analytical Chemistry 2013; 86: 655-663.

16 Chen C, Tsow F, Campbell KD, et al. A wireless hybrid chemical sensor for detection of environmental volatile organic compounds. IEEE Sensors Journal 2013; 13: 1748.

17 Zampolli S, Elmi I, Mancarella F et al. Real-time monitoring of sub-ppb concentrations of aromatic volatiles with a MEMS-enabled miniaturized gaschromatograph. Sensors and Actuators B: Chemical 2009; 141: 322-328.

18 Mohsen Y, Lahlou H, Sanchez J-B et al. Development of a micro-analytical prototype for selective trace detection of orthonitrotoluene. Microchemical Journal 2014; 114: 48-52.

19 Garg A, Akbar M, Vejerano E et al. Zebra GC: A mini gas chromatography system for trace-level determination of hazardous air pollutants. Sensors and Actuators $B$ : Chemical 2015; 212: 145-154.

20 Lewis $\mathrm{P}$, Manginell R, Adkins D et al. RG manley and GC Frye-Mason. IEEE Sensors Journal 2006; 6: 784-795.

21 Snow E, Perkins F, Houser E et al. Chemical detection with a single-walled carbon nanotube capacitor. Science 2005; 307: 1942-1945.

22 Janasek D, Franzke J, Manz A. Scaling and the design of miniaturized chemicalanalysis systems. Nature 2006; 442: 374-380.

23 Chapman PJ, Vogt F, Dutta P et al. Facile hyphenation of gas chromatography and a microcantilever array sensor for enhanced selectivity. Analytical Chemistry 2007; 79: 364-370.

24 Bulbul A, Kim H. A bubble-based microfluidic gas sensor for gas chromatographs. Lab on a Chip 2015; 15: 94-104.

25 Bae B, Kim J, Yeom J et al. Development of a portable gas analyzer using a micro-gas chromatograph/flame ionization detector (micro-GC/FID) for NASA's environmental missions. 42nd International Conference on Environmental Systems; 15-19 Jul 2012; San Diego, CA, USA; 2012: AIAA 2012-3435.

26 Chen F-Y, Chang W-C, Jian R-S et al. Novel gas chromatographic detector utilizing the localized surface plasmon resonance of a gold nanoparticle monolayer inside a glass capillary. Analytical Chemistry 2014; 86: 5257-5264.

27 Li M, Myers E, Tang H et al. Nanoelectromechanical resonator arrays for ultrafast, gasphase chromatographic chemical analysis. Nano Letters 2010; 10: 3899-3903.

28 Akbar M, Shakeel H, Agah M. GC-on-chip: Integrated column and photoionization detector. Lab on a Chip 2015; 15: 1748-1758.

29 Terry SC, Jerman JH, Angell JB. A gas chromatographic air analyzer fabricated on a silicon wafer. IEEE Transactions on Electron Devices, 1979; 26:1880-1886.

30 McNair HM, Miller JM. Basic Gas Chromatography. John Wiley \& Sons, New York, 2011.

31 Manginell RP, Bauer JM, Moorman MW et al. A monolithically-integrated $\mu \mathrm{GC}$ chemical sensor system. Sensors 2011; 11: 6517-6532.

32 Kaanta BC, Chen H, Zhang X. A monolithically fabricated gas chromatography separation column with an integrated high sensitivity thermal conductivity detector. Journal of Micromechanics and Microengineering 2010; 20: 055016.

33 Robards K, Robards K, Haddad PR et al. Principles and Practice of Modern Chromatographic Methods. Academic Press, Waltham, Massachusetts, 1994.

This work is licensed under a Creative Commons Attribution 4.0 Unported License. The images or other third party material in this article are included in the article's Creative Commons license, unless indicated otherwise in the credit line; if the material is not included under the Creative Commons license, users will need to obtain permission from the license holder to reproduce the material. To view a copy of this license, visit http://creativecommons. org/licenses/by/4.0 